\title{
Biodisel dari Minyak Nyamplung (Callophyllum inophyllum) dan Spiritus dengan Katalisator Kapur Tohor
}

\author{
Tjukup Marnoto*) dan Endang Sulistyawati \\ Jurusan Teknik Kimia, Fakultas Teknologi Industri, Universitas Pembangunan Nasional Veteran, \\ Jalan SWK 104 Lingkar Utara, Condongcatur, Yogyakarta 55283
}

Diterima 18-08-2010 Disetujui 27-11-2010

\begin{abstract}
Production of biodiesel has been done by many institutions; however the materials used are usually competed with food such as palm oil, therefore it has lesser economical value. The use of Callophyllum inophyllum plant in Indonesia is very limited and the seeds are usually thrown away the contain high oil relatively. This plant is relatively easy to grow and has seasonal fruiting mostly planted as shading plant in rural area and also as land slide resisting plant. The plant is normally utilized for light construction and burning wood. The technology for producing biodiesel is simple and can be easily introduced to the society. Biodiesel produced from easily obtained and low cost materials will improve a society's energy independency and well-being. This paper presents the process of producing biodiesel from Callophyllum inophyllum oil and rubbing alcohol using superficial lime (CaO) as the solid catalyst that is cheap and easily obtained, therefore this technology can be easily transferred to the society and will improve the economical value of the plant. Referring to the varieties used, relatively good condition was at $1: 3 \mathrm{~mol}$ ratio of Callophyllum inophyllum oil to rubbing alcohol and the amount of catalyst used was $0.3-0.5 \%$ of the rubbing alcohol. Physical characteristics of the produced biodisel were such as specific gravity at $60 / 60^{\circ} \mathrm{F}$ was 0.870 , flash point P.M.cC was $195^{\circ} \mathrm{C}$ and pour point was $4^{\circ} \mathrm{C}$.
\end{abstract}

Keywords: biodiesel, callophyllum inophyllum, renewable energy

\section{PENDAHULUAN}

Energi merupakan kebutuhan hidup orang banyak, sehingga keperluan akan energi terus meningkat sesuai dengan perkembangan penduduk dunia dan teknologi. Sampai saat ini, umumnya kebutuhan energi dipenuhi oleh sumber energi fosil, seperti bahan bakar minyak dan batubara. Keberadaan sumber energi fosil semakin menipis sedangkan jumlah penduduk dunia semakin meningkat. Sehingga perlu dicari sumber-sumber energi alternatif yang baru dan terbarukan. Banyak penelitipeneliti di dunia yang melakukan penelitian energi baru dan terbarukan seperti sumber energi panas matahari, osean, hidro, angin, geotermal, maupun bioenergi. Bioenergi diantaranya biomassa, biotermal, bioetanol dan biodisel. Biodisel dibuat dari transesterifikasi minyak nabati dan alkohol.

Beberapa bahan baku untuk pembuatan biodisel antara lain minyak kelapa sawit, kedelai, bunga matahari, jarak pagar, dan beberapa jenis tumbuhan lainnya (Alonso et al., 2007; Han et al., 2005; Handayani, 2005; Kouzu et al., 2008; Ni \& Meunier 2007; Xuejun Liu et al., 2008; Yoeswono et al., 2008).

\footnotetext{
*Telp: +62274486889

Email: tjukup@gmail.com
}

Ada dua kendala utama dalam pembuatan biodisel yaitu dari segi bahan baku dan proses pembuatan seperti penggunaan bahan baku minyak sawit atau minyak bunga matahari harganya fluktuatif karena juga digunakan sebagai bahan pangan sehingga tidak ekonomis, sedangkan minyak jarak memiliki kendala pada pasokan bahan baku (Suhaya, 2008). Perlu dicari dan diteliti minyak tanaman lainnya yang dapat dijadikan bahan baku biodisel seperti nyamplung (Callophyllum inophyllum). Minyak nyamplung umumnya belum diproduksi karena tidak dikonsumsi oleh manusia. Pohon dan buah nyamplung ditunjukkan pada Gambar 1.
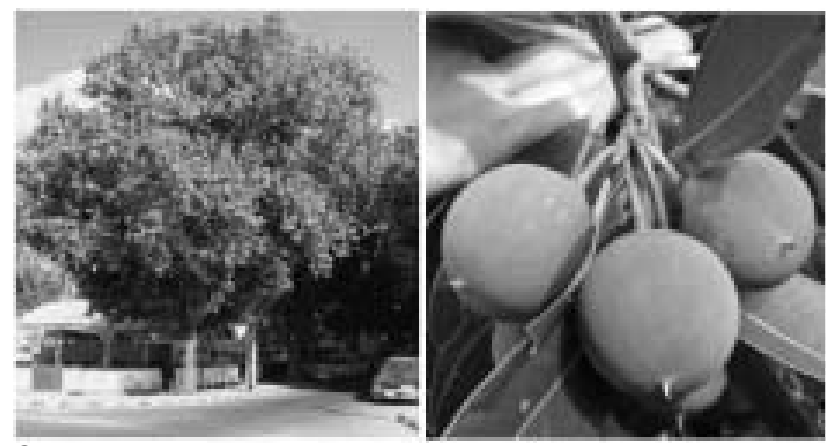

Gambar 1: Foto pohon dan buah nyamplung 
Masyarakat Indonesia memanfaakan tumbuhan nyamplung atau kosambi (Indonesia), bintangor (Malaysia), poon (India) yang mempunyai nama latin Callophyllum inophyllum, hanya untuk diambil kayunya sebagai kayu bakar atau kontruksi ringan dan sebagai tanaman hias maupun perindang. Buah nyamplung masih kurang dimanfaatkan dan hanya terbuang percuma, padahal kandungan minyak nabati di dalam buah nyamplung antara 40\% - 73\% (Elbert et al., 2003). Tanaman ini sangat mudah tumbuh berkembang dan belum terlihat hama tanaman yang berarti, sehingga sangat mudah untuk dibudidayakan. Kendala yang ada pada pemanfaatan buah nyamplung yaitu tanaman ini berbuah musiman.

Proses pembuatan biodisel dikenal dengan proses transesterifikasi antara asam lemak bebas dalam minyak nabati dengan alkohol. Alkohol yang relatif baik dan sering digunakan adalah metanol dan etanol. Etanol sering dimanfaatan sebagai pembuatan minuman keras yang memabukan, oleh karena itu penjualan etanol dikenakan cukai sehingga harganya relatif mahal. Penjualan etanol yang tidak dikenakan cukai dan mudah didapat di lingkungan masyarakat adalah spiritus yaitu campuran etanol, sedikit metanol, dan minyak tanah agar tidak dimanfaatkan untuk membuat minuman yang memabukan, atau tidak disalah gunakan. Teknologi pembuatan biodisel bisa menggunakan katalis cair dan padat (homogen dan heterogen). Kebanyakan proses tersebut menggunakan katalis cair, dengan kendala yaitu pada pemisahan gliserol sebagai hasil samping karena mudah larut dalam air yang terkandung dalam katalis. Penggunaan katalis padat (heterogen) lebih memudahkan pemisahan gliserol dan katalis, sehingga menghasilkan gliserol lebih murni dibanding proses katalis cair. Gliserol mempunyai nilai ekonomis tinggi maka proses penggunaan katalis padat akan lebih menguntungkan (Kouzu et al., 2008; Marchetti et al., 2008). Dengan tujuan memasyarakatkan pengadaan biodisel, penelitian ini akan dicoba menggunakan spiritus untuk transesterifikasi minyak nyamplung dengan katalis padat kapur tohor. Bahan-bahan ini semuanya relatif murah dan mudah didapat.

Pada prinsipnya, proses transesterifikasi adalah mengeluarkan glicerin dari minyak dan mereaksikan asam lemak bebasnya dengan alkohol menjadi alkohol ester (Fatty Acid Methyl Ester) atau biodisel (Yoeswono et al., 2008).
Teknologi ini sangat mudah dikenalkan dan diterapkan kepada masyarakat luas, diharapkan akan meningkatkan kesejahteraan masyarakat Indonesia.

Reaksi transesterifikasi minyak nabati dengan metanol mengikuti persamaan reaksi sebagai berikut :

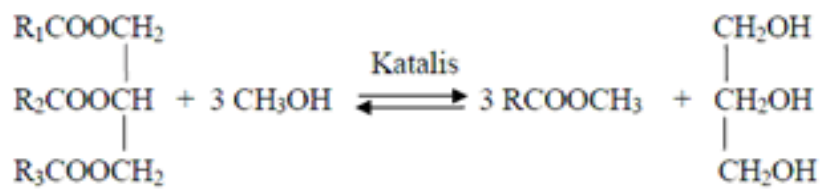

Spiritus adalah bahan bakar yang terdiri dari campuran etanol, metanol dan minyak tanah (kerosin). Alkohol (metanol dan etanol) mempunyai sifat aseotrop dengan air sehingga spiritus mengandung sedikit air, minyak tanah atau kerosin saling melarutkan dengan ester dan keduanya tidak larut terhadap air dan gliserol. Tercampurnya sedikit kerosin pada biodisel tidak bermasalah pada penggunaan bahan bakar disel, karena minyak solar sebagai bahan bakar disel juga bahan dasarnya sama dengan kerosin (NN, 1995) sehingga tidak perlu dilakukan pemisahan. Sedangkan penggunaan gliserol harus dipisahkan dengan katalis yang digunakan. Reaksi tranesterifikasi minyak nyamplung dengan spiritus menggunakan katalis kapur tohor mengikuti persamaan reaksi sebagai berikut:

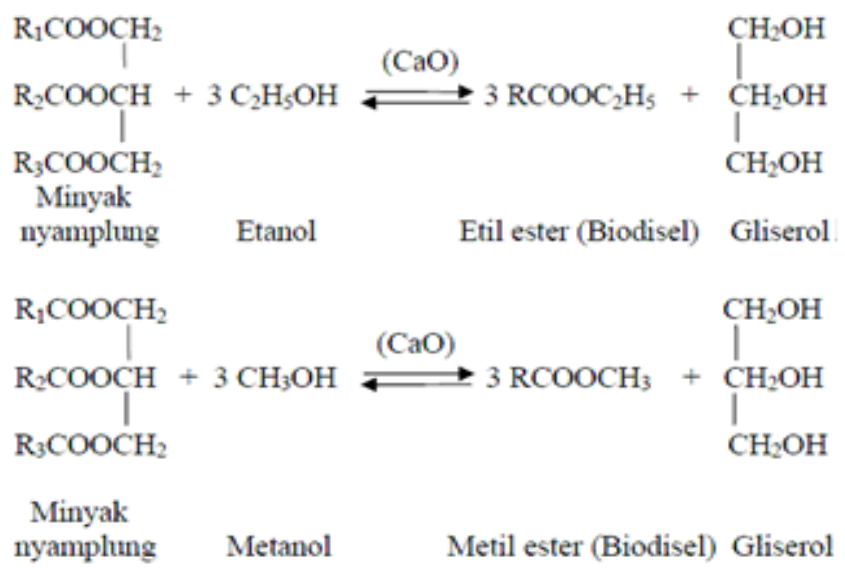

\section{BAHAN DAN METODE}

Bahan yang digunakan dalam penelitian adalah minyak nyamplung, spiritus, dan kapur tohor $(\mathrm{CaO})$. Minyak nyamplung, dibuat dari bijih nyampung kering dan ditekan untuk keluar minyaknya, untuk mengetahui komposisi kimia minyak nyamplung dianalisa menggunakan gas kromatografi (GC).

Spiritus, didapat dari pengecer dengan komposisi yang tertera pada label adalah Etanol $89,45 \%$; methanol $2,11 \%$; dan kerosin $8,44 \%$ (\% volume). Katalis kapur tohor adalah $(\mathrm{CaO})$ hasil kalsinasi batu gamping yang 
didapat dari pembakaran batu gamping atau disebut tobong gamping di jalan Ring-Road Selatan Yogyakarta. Penggunaan kapur tohor pada bahan bangunan biasanya setelah dibakar kemudian disiram dengan air sehingga sedikit mengandung $\mathrm{Ca}(\mathrm{OH})_{2}$. Kapur Tohor yang digunakan pada penelitian ini, adalah hasil pembakaran yang belum disiram dengan air (suka air).

Alat-alat yang digunakan dalam penelitian ini yaitu labu leher tiga sebagai reaktor (batch), pengaduk, pendingin balik, termometer, water, bath, stopwatch, tachometer, dan timbangan elektrik. Skema rangkaian alat-alat yang digunakan dapat dilihat pada Gambar 2.

Pembuatan minyak bijih nyampung dilakukan dengan mengambil biji buah nyamplung yang ada didalam tampurung, kemudian dipotong-potong dan dijemur sehari atau diangin-angin (dikeringkan), kemudian dipres dan keluar minyaknya (Gambar 3).

Transesterifikasi minyak nyamplung dilakukan dengan memanaskan minyak pada suhu sekitar $60^{\circ} \mathrm{C}$ di dalam labu. Bersamaan itu spiritus dan katalisator dipanaskan dengan perbandingan berat tertentu di dalam erlenmeyer pada suhu $60^{\circ} \mathrm{C}$. kemudian

Biji buah nyamplung diambil dari dalam tempurung buah

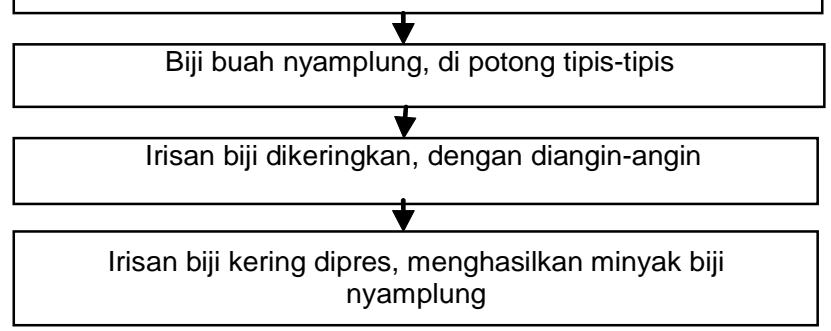

Gambar 2. Skema pembuatan minyak biji nyamplung

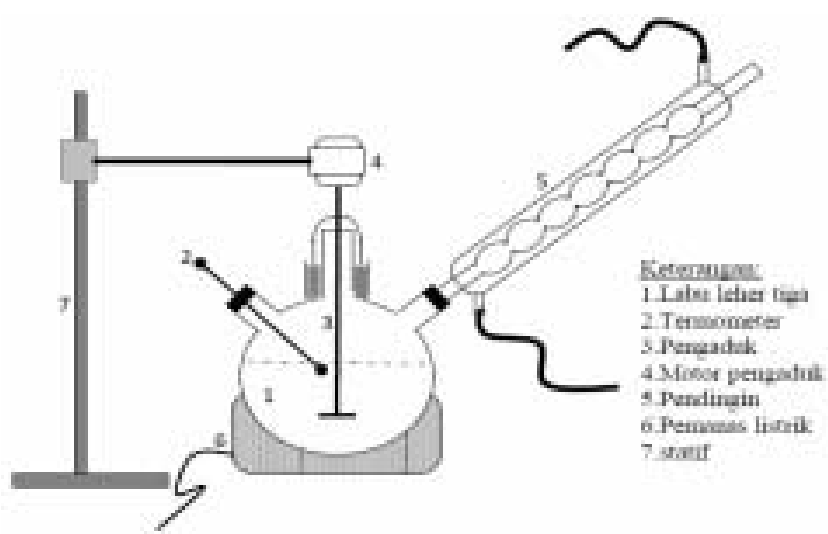

Gambar 3. Skema rangkaian alat penelitian

Tabel 1. Komposisi kimia minyak nyamplung

\begin{tabular}{lc}
\multicolumn{1}{c}{ Nama trivial (sistematik); akronim } & Asam lemak dalam minyak nyamplung (\%) \\
\hline Asam palmitat (asam heksadekanoat);16:0 & 14,24 \\
Asam oleat (asam oktadekenoat); C18:1 & 68,37 \\
Asam stearat (asam oktadekanoat); C18:0 & 16,67 \\
Asam erucate (asam docosanoat); C23:0 & 0,15 \\
Asam heneikosanoate (asam heneikosanoat); C22:0 & 0,49 \\
Asam arakidat (asam eikosanoat); C20:0 & 0,07 \\
\hline
\end{tabular}

direaksikan kedua reaktan tersebut dengan perbandingan antara minyak dan spiritus tertentu dan diaduk dengan kecepatan 2000 rpm, kondisi dijaga konstan. Sampel diambil sebanyak $15 \mathrm{ml}$, pada selang waktu tertentu, kemudian lapisan biodisel dipisahkan dari gliserol menggunakan corong pemisah, lalu dicuci dengan aquadest. Ester dan air pencuci dipisahkan dengan cara sentrifugasi dengan kecepatan putaran 1600 rpm selama 15 menit. Hasil biodisel dianalisis menggunakan GC, analisa secara fisik dilakukan dengan metode-metode ASTM D 1298, D93, dan D97.

\section{HASIL DAN PEMBAHASAN}

Hasil analisa bahan baku minyak nyamplung dengan gas kromatografi (GC) ditunjukkan pada Gambar 4. Kandungan lemak pada minyak nyamplung ditunjukkan pada Tabel 1. Asam lemak yang terkandung adalah asam stearat $(16,67 \%)$ dan asam oleat $(68,37 \%)$. Berdasarkan data-data komposisi kimia dapat dihitung berat molekul minyak nyamplung yaitu $704,2 \mathrm{~g} / \mathrm{mol}$. Penelitian dilakukan dengan variasi perbandingan mol minyak nyamplung dengan spiritus $(1: 3,1: 5,1: 7,1: 9$ dan 1:11), dan variasi kadar katalis terhadap spiritus $(0,3 \%, 0,5 \%, 1 \%, 1,5 \%$, dan $2 \%$ berat $\mathrm{CaO} /$ spritus).

Variabel perbandingan mol dilakukan pada kadar katalis $0,5 \%$ berat $\mathrm{CaO} /$ spiritus yaitu kadar katalis terbaik pada penelitian ini, sedangkan variasi kadar katalis dilakukan pada perbandingan mol minyak dan $6,518,320$

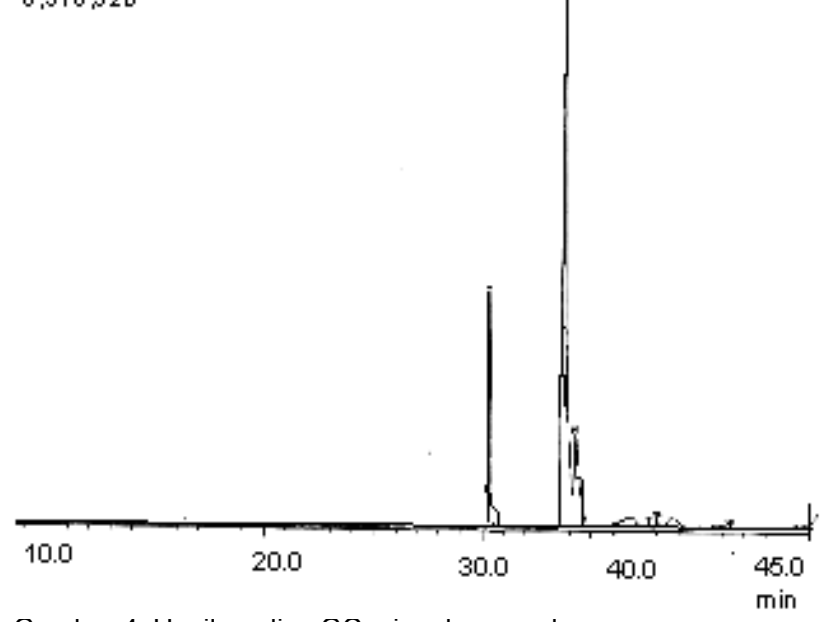

Gambar 4. Hasil analisa GC minyak nyamplung 
spiritus stokhiometri. Hasil biodisel dari berbagai variasi dilakukan analisa dengan GC, beberapa hasil analisa ditunjukkan pada Gambar 5 dan 6. Pengolahan data-data tersebut, dapat dihitung konsentrasi hasil biodisel dan gliserol juga konversi reaksi transesterifikasi, hasilnya ditunjukkan pada Gambar 7 dan 8.

Pengaruh penggunaan kadar katalis yang dilakukan pada rasio mol minyak nyamplung:spiritus sama dengan 1:5, pengadukan $2000 \mathrm{rpm}$ dan temperatur operasi $60^{\circ} \mathrm{C}$, terhadap konversi transesterifikasi minyak nyamplung, konsentrasi biodisel dan gliserol dapat dilihat pada Gambar 7. Konversi reaksi pada variasi kadar katalis antara $0,3 \%$ hingga $2 \%$ adalah 0,6415 hingga 0,6842 atau relatif sama bahkan pada kadar $2 \%$ kembali 0,5415. Namun demikian pada konsentrasi semakin tinggi hasil gliserol menurun, padahal secara stokhiometri produk gliserol semestinya hampir sama, hal ini dikarenakan semakin banyak kadar katalis maka gliserol akan terjerap pada katalis bersama air, sehingga setelah disaring perolehan gliserol menurun, karena ada yang terikut pada katalis.

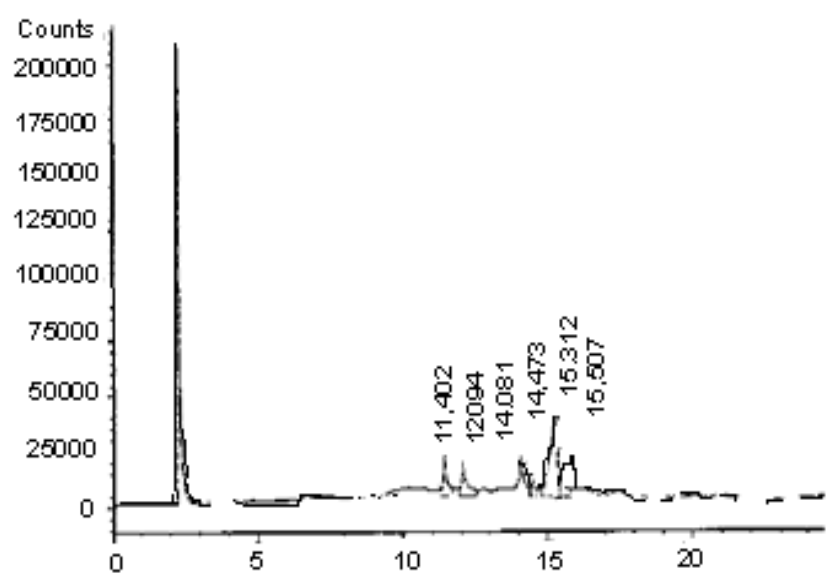

Gambar 5. Hasil analisa GC biodisel pada perbandingan mol minyak nyamplung dan spiritus $1: 5$, kadar katalis $0,5 \%$

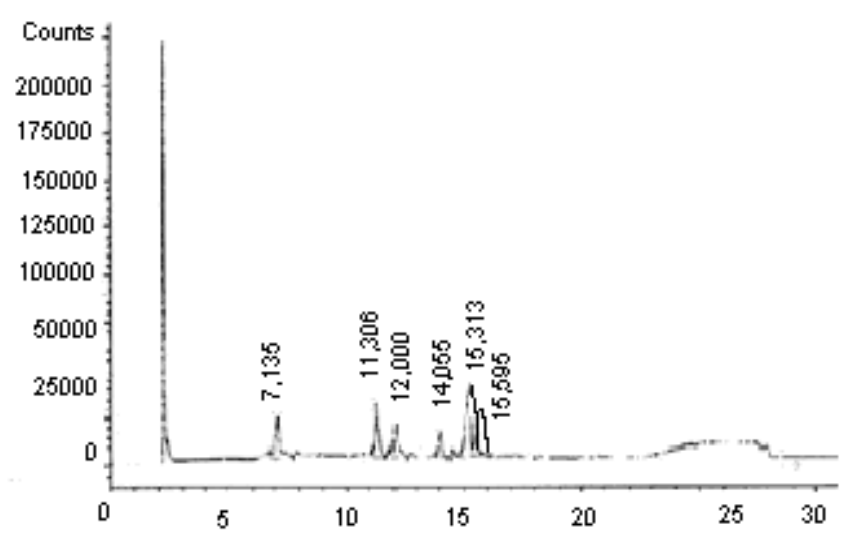

Gambar 6. Hasil analisa GC biodisel pada perbandingan mol minyak nyamplung dan spiritus $1: 3$, kadar katalis $0,5 \%$
Dengan kata lain bahwa variasi kadar katalis tidak berpengaruh secara signifikan terhadap konversi reaksi taranssesterifikasi, namun semakin besar kadar katalis akan menurunkan perolehan hasil samping gliserol. Dapat disimpulkan sementara penggunaan katalis kapur tohor pada reaksi transesterifikasi dengan reaktor batch cukup antara 0,3-0,5\% berat katalis terhadap berat spiritus (alkohol).

Pengaruh perbandingan mol minyak nyamplung dengan spiritus berkatalis yang dilakukan pada kadar katalis $0,5 \%$ berat/spiritus, kecepatan pengadukan $2000 \mathrm{rpm}$ dan temperatur $60^{\circ} \mathrm{C}$, terhadap konversi reaksi transesterifikasi minyak nyamplung, konsentrasi hasil biodisel dan gliserol ditunjukkan pada Gambar 8. Variasi rasio mol minyak nyamplung terhadap spiritus dilakukan antara 1:3 sampai 1:11, konversi reaksi yang dihasilkan sekitar 0,6, secara teori semakin banyak reaktan yang digunakan akan menggeser kesetimbangan kearah produk, dan konversi akan meningkat. Gambar 8 juga meperlihatkan bahwa jumlah produk gliserol yang dihasilkan menurun walaupun konversi reaksi relatif tetap, hal ini disebabkan gliserol terjerap katalis semakin banyak karena spiritus mengandung katalis $(0,5 \%)$. Gliserol secara fisik lebih kental dibandingkan

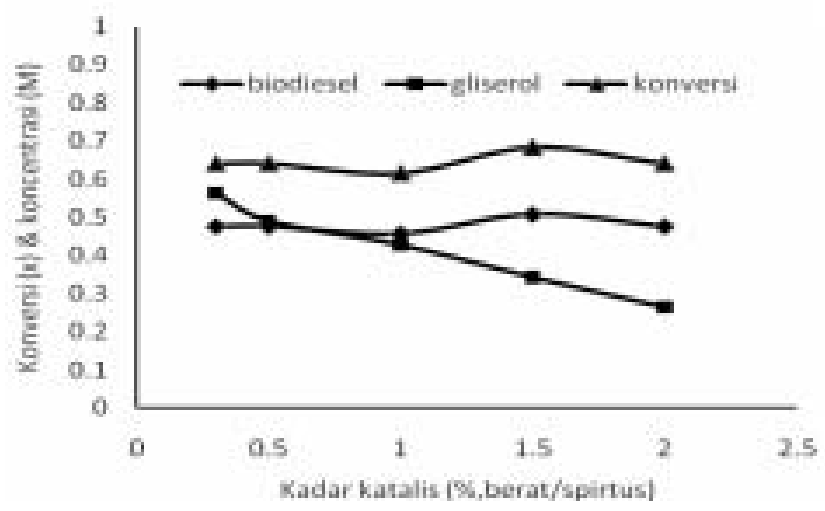

Gambar 7. Konversi minyak nyamplung, kosentrasi biodisel dan gliserol, terhadap kadar katalis

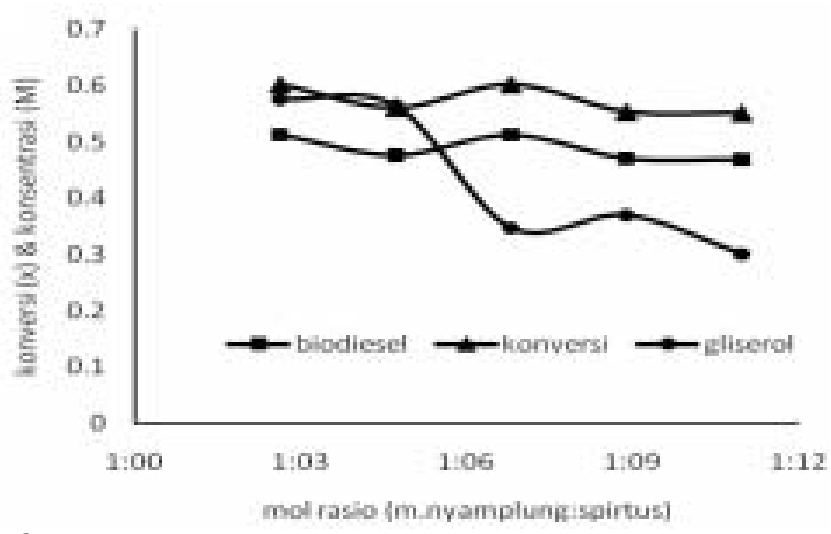

Gambar 8. Konversi minyak nyamplung, kosentrasi hasil biodisel dan gliserol, terhadap variasi rasio mol reaktan 
etanol sehingga gliserol yang terjerap ke dalam katalis sukar untuk mobilisasi alkohol (reaktan etanol dan metanol) di dalam pori, maka terjerapnya gliserol akan membuat aktivitas katalisator terbatas, sehingga konversi reaksi seolah hanya terbatas sekitar 0,6. Untuk mengaktifkan kembali perlu dilakukan kalsinasi, namun karena kapur tohor relatif murah dan mudah didapat hal tersebut tidak perlu dilakukan.

Hasil proses pada rasio atau perbandingan mol yang berlebihan, tampak secara fisik hasil proses terbetuk 3 lapisan yaitu lapisan paling atas adalah spiritus sisa yang ditengarai oleh warna spiritus, lapisan kedua adalah biodisel dan paling bawah adalah lapisan gliserol dan katalis hal tersebut akan menyulitkan proses pemisahan dan pencucian. Hasil pada rasio mol minyak nyamplung 1:3 (stokhiometri) hanya terbentuk dua lapis yaitu lapisan atas biodisel dan lapisan bawah katalis dan gliserol (Gambar 9). Dari pembahasan kedua data tersebut dapat dikatakan bahwa penggunaan katalis padat kapur tohor dengan reaktor batch dalam penelitian ini, konversi reaksi transesterifikasi maksimum tercapai hanya 0,6842 atau rata-tara konversi sekitar 0,6. Proses ini cukup memakai rasio mol reaktan secara stokhiometri (1:3) dan penggunaan kadar katalis antara 0,3-0,5\% berat katalis/spiritus.

Hasil-hasil biodisel secara fisik/kenampakan relatif sama, secara teori masih mengandung lemak/minyak yang belum bereaksi. Untuk keperluan bahan bakar biodisel, dilakukan analisis sifat fisis diantaranya adalah Specific gravity (spgr), Flash point dan Pour Point. Data sifat fisik ditunjukkan pada Tabel 2. Berdasarkan dari batas-batas (minimum dan maksimum) maka biodisel

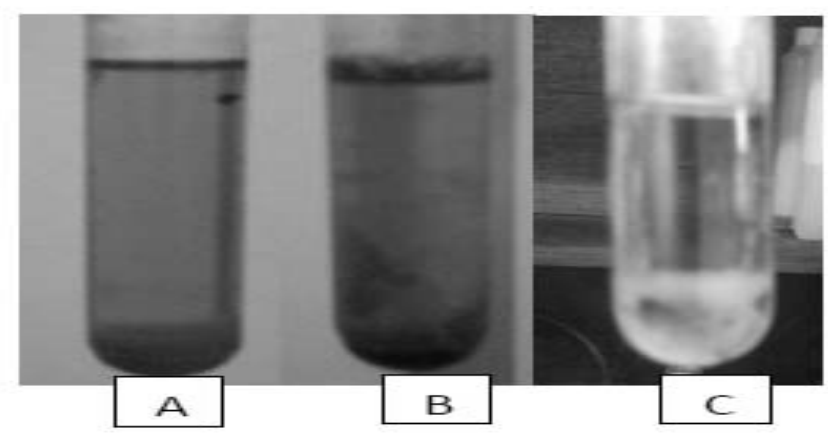

Gambar 9. Foto hasil proses, A: lapisan atas biodisel, bawah gliserol dan katalis. B: Lapisan atas spiritus, tengah biodisel, bawah gliserol dan katalis. C: lapisan biodisel dan gliserol setelah disaring hasil penelitian ini memenuhi syarat untuk bahan bakar mesin disel.

\section{KESIMPULAN}

Proses pembuatan biodisel dari minyak nyamplung dan spiritus dengan katalisator kapur tohor dapat dilakukan dengan reaktor batch. Rasio reaktan cukup dilakukan secara stockhiometri (minyak nyamplung : spiritus = 1:3) dan kadar katalis adalah 0,3-0,5\% berat katalis/spiritus. Gliserol yang dihasilkan mudah dipisahkan dengan dekanter dan filtrasi untuk memisahkan dari katalis. Ester-ester yang dihasilkan berdasarkan sifat fisik memenuhi sebagai bahan bakar biodisel. Kualitas biodisel dari minyak nyamplung adalah specifik grafity $60 / 60^{\circ} \mathrm{C}=0,870$; Flash point $=$ $195^{\circ} \mathrm{C}=195$; dan Pour Point $=4^{\circ} \mathrm{C}$, nilai-nilai tersebut memenuhi batas-batas minimum dan maksimum dari bahan bakar mesin disel.

Teknologi ini sangat mudah dan murah, serta dapat ditransfer ke masyarakat menengah ke bawah, dengan bahan-bahan yang mudah didapat di lingkungan masyarakat. Aplikasi teknologi ini kepada masyarakat dapat meningkatkan ketahanan energi nasional dan dapat meningkatkan kesejahteraan masyarakat.

\section{UCAPAN TERIMAKASIH}

Penghargaan dan terimakasih disampaikan kepada Kementrian Pendidikan Nasional Republik Indonesia dan Panitia pelaksana Hibah Kompetensi A2 , atas biaya penelitian ini melalui proyek Hibah Kompetensi A-2 prodi Teknik Kimia, Universitas Pembangunan Nasional "Veteran" Yogyakarta dengan Nomor Kontrak: 1666/KPIPT/VII/2008 Tanggal 28 Juli 2008.

\section{DAFTAR PUSTAKA}

Alonso, D.M., Mariscal, R., Moreno-Tost, R., Poves, Z.M.D. \& Granados, M.L. 2007. Potassium leaching during triglyceride transesterification using $\mathrm{K} / \mathrm{c}-\mathrm{Al} 2 \mathrm{O} 3$ catalysts, Catalysis Communications 8: 2074-2080.

Han, H., Chao, W. \& Zhang, J. 2005. Preparation of biodisel from soybean oil using supercritical methanol and $\mathrm{CO}_{2}$ as cosolvent. Process Biochemistry 40: 3148-3151.

Handayani, T. 2005. Pembuatan Drying Oil dari Minyak Jarak. Fakultas Teknologi Industri, ITB, Bandung.

Kouzu, M., Kasuno, T., Tajika, M., Sugimoto, Y., Yamanaka, S. \& Hidaka, J. 2008. Calcium oxide as a solid base catalyst for transesterification of soybean oil and its application to biodisel production. Fuel 87: 2798-2806.

Tabel 2. Sifat fisis biodisel dari minyak Nyamplung

\begin{tabular}{clcccc}
\hline No. & \multicolumn{1}{c}{ Sifat Fisis biodisel } & Hasil analisa & Metode Analisa & Batas Min Maks \\
\hline 1. & Specific gravity at 60/60 $\mathrm{F}$ & 0,870 & ASTM D 1298 & 0,840 \\
2. & Flash point P.M.cc, ${ }^{0} \mathrm{C}$ & 195 & ASTM D 93 & - \\
3. & Pour Point, ${ }^{\circ} \mathrm{C}$ & 4 & ASTM D 97 & 150 \\
\hline
\end{tabular}


Marchetti, J.M., Miguel, V.U. \& Errazu, A.F. 2008. Technoeconomic study of different alternatives for biodiesel production. Fuel Processing Technology 89: 740-748.

Elbert, L., Little, Jr. \& Roger, G. 2003. Kamani (Calophyllum inophyllum). Agriculture Handbook, Tropical Agriculture and Human Resources, University of Hawai, Manoa.

Ni, J. \& Meunier, F.C. 2007. Esterification of Free Fatty Acids in Sunflower Oil Over Solid acid Catalysts Using Batch and Fixed bed-reactors. Applied Catalysis A: General 333: 122130.

Anonim. 1995. Kamus Minyak dan Gas Bumi. 3 ed, Pusat Penelitian dan Pengembangan Teknologi Minyak dan Gas Bumi, LEMIGAS.
Rahayu, M. 2006. Teknologi Proses Produksi Biodisel", Prospek Pengembangan Bio-fuel sebagai Substitusi Bahan Bakar Minyak 17-2.

Suhaya, D. 2008. Para Kandidat Biodisel, www/ dedesuhaya.blogspot.com (Juli 2008).

Yoeswono., Triyono. \& Iqmal Tahir. 2008. Kinetics of Palm Oil Transesterification in Methanol with Potassium Hydroxide as a Catalyst. Indo. Journal Chem 8(2): 219-225.

Xuejun Liu., Huayang He., Yujun Wang., Shenlin Zhu. \& Xianglan Piao. 2008. Transesterification of soybean oil to biodiesel using $\mathrm{CaO}$ as a solid base catalyst. Fuel 87: 216221. 